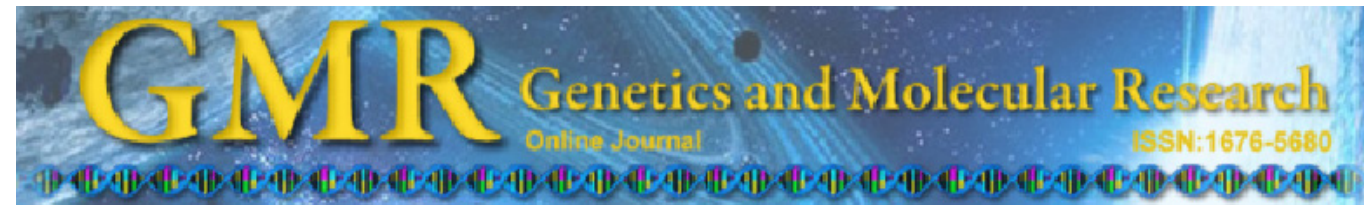

\title{
Assessing wheat (Triticum aestivum) genotypes for "Yr" resistance genes using conserved regions and simple-sequence motifs
}

\author{
E. Cabuk ${ }^{1}$, Y. Aydin ${ }^{1}$ and A.A. Uncuoglu ${ }^{2}$ \\ ${ }^{1}$ Department of Biology, Faculty of Science and Letters, Marmara University, \\ Istanbul, Turkey \\ ${ }^{2}$ Department of Bioengineering, Faculty of Engineering, Marmara University, \\ Istanbul, Turkey \\ Corresponding author: A.A. Uncuoglu \\ E-mail: ahu.uncuoglu@marmara.edu.tr
}

Genet. Mol. Res. 10 (4): 3463-3471 (2011)

Received January 15, 2011

Accepted September 2, 2011

Published December 5, 2011

DOI http://dx.doi.org/10.4238/2011.December.5.2

\begin{abstract}
Analysis of DNA sequence variation among genotypes is useful for differentiation of wheat accessions, selection strategies and genetic development of crop plants. We screened molecular markers for yellow rust resistance genes $(\mathrm{Yr} 7, \mathrm{Yr} 9, \mathrm{Yr} 15, \mathrm{Yr} 18, \mathrm{Yr} 26$, and $\mathrm{YrH} 52)$, which are in the gene-rich regions of wheat chromosomes 1B, 2B, and $7 \mathrm{D}$, to investigate DNA sequence differences and repeat motifs and numbers between wheat cultivars resistant (Izgi2001, Sonmez2001, PI178383) and susceptible (Aytin98, ES14, Harmankaya99) to yellow rust. The $\mathrm{F}_{2}$ individuals derived from the crosses were evaluated for yellow rust resistance at both the seedling and adult stages to identify DNA markers genetically linked to yellow rust resistance. The most repeated motif was found to be GA and the least repeated motif TAGA among the cultivars. When we examined DNA sequence differences (insertion, deletion and single nucleotide changes), the molecular markers $\mathrm{Xgwm} 526(\mathrm{Yr} 7)$ and $\mathrm{Xgwm} 273$ (YrH52) were found to have the most conserved regions and $\operatorname{Yr} 15$ (Xgwm413) the least conserved regions among the cultivars. This DNA sequence information can be
\end{abstract}


used for selection of suitable parents, creating mapping populations and developing molecular markers associated with yellow rust resistance in plant breeding programs.

Key words: DNA sequence; Gene-rich region; Molecular marker; Resistance; Yellow rust

\section{INTRODUCTION}

Yellow rust caused by Puccinia striiformis f.sp. tritici, is one of the most devastating diseases of wheat (Triticum aestivum L.) throughout the world. The use of fungicides to control disease has some drawbacks such as cost of the chemicals, limited shelf life, negative effects on the environment, and acquired resistance of the pathogen to applied chemicals. Therefore, growing genetically resistant cultivars has been the main mechanism and the most economical method to control the disease.

Environmental effects on expression of quantitative resistance make selection and pyramiding of R-genes and quantitative trait loci (QTLs) for rust resistance difficult, but pyramiding can be greatly aided by the use of molecular markers closely linked to the gene/QTL. These markers can be readily identified using a rapid, high-through-put screening procedure as part of the breeding program, an approach referred to as marker-assisted selection (MAS) (McDowell and Woffenden, 2003). The genomic abundance of microsatellites and their ability to be associated with many phenotypes, make this class of molecular markers a powerful tool for diverse application in plant genetics (Maia et al., 2009).

Microsatellites show a much higher level of polymorphism and informativeness in hexaploid bread wheat than any other marker system (Roder et al., 1998). The efficiency of microsatellite marker development depends on the abundance of repeats in the target species and the ease with which these repeats can be developed into informative markers. The wheat genome is extremely large $\left(16 \times 10^{9} \mathrm{bp} / 1 \mathrm{C}\right)$ and contains much repetitive DNA (more than $80 \%$ ) (Bennett and Smith, 1976). At many microsatellite loci, a high frequency of variation in the number of repeat units has been observed (Tautz et al., 1986). This makes microsatellites an abundant source of highly polymorphic and codominant genetic markers. Microsatellites are hot spots for genome mutation and variation (Weber, 1990; Ellegren, 2004). The variability seen in microsatellites is primarily due to sequence length polymorphisms caused by variable numbers of tandem repeats (Ellegren, 2000, 2004; Neff and Gross, 2001). Based on genomic library screening, it was observed that, in plants, $(\mathrm{AG} / \mathrm{TC})_{\mathrm{n}}$ is more frequent than $(\mathrm{AC} / \mathrm{TG})_{\mathrm{n}}$, (Lagercrantz et al., 1993), whereas in humans $(\mathrm{AC} / \mathrm{TG})_{\mathrm{n}}$ repeats are the most common (Weber and May, 1989). Akkaya et al. (1992) indicated that (AT) $)_{\mathrm{n}}$ and (ATT) microsatellite repeat motifs were the most frequent in soybean. Similarly, Morgante and Olivieri (1993) confirmed that AT repeat motif was the most common in plants, shown in many studies they have done.

In this study, DNA sequence analysis was performed with primers derived from microsatellite markers linked to $\mathrm{Yr}$ genes in gene-rich regions of wheat chromosomes. The most conserved regions and single nucleotide polymorphisms were detected, and sequence analyses were also carried out. As an extremely conservative sequence in most plant introns, the CACGC sequence greatly increases the probability of a full match between primers and templates in the 
PCR reaction. In surveying conserved regions, single nucleotide polymorphisms are potent (Shaheen et al., 2010). The property of SNP markers is to discriminate alleles at the level of individual organisms (Nakitandwe et al., 2007).

The objectives of this study were to analyze repeat motifs and numbers and to determine DNA sequence differences among the wheat cultivars in terms of molecular markers showing a genetic link to $\mathrm{Yr}$ genes $(\mathrm{Yr} 7, \mathrm{Yr} 9, \mathrm{Yr} 15, \mathrm{Yr} 18, \mathrm{Yr} 26, \mathrm{YrH52})$ in gene-rich regions of wheat chromosomes 1B, 2B, 7D.

\section{MATERIAL AND METHODS}

\section{Plant material}

Six homozygous bread wheat genotype (Triticum aestivum L. cvs. PI178383, Izgi2001 and Sonmez2001-known yellow rust resistant cultivars, and Triticum aestivum L. cvs. Harmankaya99, ES14 and Aytin98- known yellow rust susceptible cultivars) obtained from Anatolian Agricultural Research Institute, Eskisehir, Turkey was used as plant material. The resistance of parental cultivars and $\mathrm{F}_{2}$ generations were tested in the greenhouse by applying uredospores. Two weeks following the inoculation, the infection type was recorded using the 0-9 scale (McNeal et al., 1971), treating 0-6 as low infection type and 7-9 as high infection type. The disease score of PI178383, Izgi2001, and Sonmez2001 was 0 while that of Harmankaya99, ES14, and Aytin98 was 8 in greenhouse assays. These assays confirm that the parental genotypes greatly differ in their resistance to yellow rust disease.

\section{Analysis of molecular markers linked to $\mathrm{Yr}$ genes in gene-rich regions}

Leaves from resistant and susceptible plants were used for total genomic DNA extraction using the method of Weining and Landridge (1991), modified by Song and Henry (1995). Bread wheat genotypes were screened by molecular markers (Xgwm526, Xgwm582, Xgwm413, Xgwm295, Xgwm18, Xgwm11 and Xgwm273) located in gene-rich regions of wheat linked to $\mathrm{Yr}$ genes $(\mathrm{Yr} 7, \mathrm{Yr} 9, \mathrm{Yr} 15, \mathrm{Yr} 18, \mathrm{Yr} 26, \mathrm{Yr} 26$ and $\mathrm{YrH52}$ ) (Table 1). DNA amplifications were carried out in $25-\mu \mathrm{L}$ reaction mixtures, each containing $1 \mathrm{X}$ Taq Buffer (MBI Fermentas, Germany), $0.4 \mathrm{mM}$ forward primer, $0.4 \mathrm{mM}$ reverse primer, $0.2 \mathrm{mM}$ dNTPs (MBI Fermentas, Germany), $2.5 \mathrm{mM} \mathrm{MgCl}{ }_{2}$ (MBI Fermentas, Germany), $0.625 \mathrm{U} / \mu \mathrm{L}$ Taq polymerase (MBI Fermentas EP0402, Germany) and $100 \mathrm{ng}$ template DNA. The following PCR profile was used in an Eppendorf Mastercycler Gradient machine; initial denaturation at $94^{\circ} \mathrm{C}$ for $3 \mathrm{~min} ; 40 / 45$ cycles at $94^{\circ} \mathrm{C}$ for $1 \mathrm{~min}, 50^{\circ} \mathrm{C} / 55^{\circ} \mathrm{C}$ for $1 \mathrm{~min}, 72^{\circ} \mathrm{C}$ for $2 \mathrm{~min}$; and a final extension at $72^{\circ} \mathrm{C}$ for $10 \mathrm{~min}$. The amplification products were resolved on a $2 \%$ agarose gel. To determine the size of PCR products, a 100-bp DNA ladder marker (MBI Fermentas SM0323, Germany) and 50-bp DNA ladder marker (MBI Fermentas SM0371, Germany) were used.

\section{Sequence analysis of the DNA fragments}

PCR products obtained by Xgwm526 (Yr7), Xgwm582 (Yr9), Xgwm413 (Yr15), 
Xgwm295 (Yr18), Xgwm11 (Yr26), Xgwm18 (Yr26), and Xgwm273 (YrH52) were separated on a $6 \%$ polyacrylamide sequencing gel. The fragment showing a polymorphic profile for the yellow rust resistant genotypes was cut out from the gel and cloned into PCR cloning vector (pGEMT-Easy Vector Systems, Promega). Following E.coli bacterial transformation and blue-white colony screening, positive white colonies were analyzed for the presence of the fragment by PCR with T7 vs SP6 universal primers. The recombinant plasmid was harvested using the Qiagen, QIAprep Spin Miniprep kit. Sequence analysis of the fragment was performed on the isolated plasmid with M13-47 sequencing primer using GenomeLab GeXP Genetic Analysis System (Beckman Coulter) according to manufactur instructions.

\begin{tabular}{|c|c|c|c|c|}
\hline Name of primer & Linked $Y r$ gene & Forward primer $\left(5^{\prime}-3^{\prime}\right)$ & Reverse primer $\left(5^{\prime}-3^{\prime}\right)$ & $\mathrm{T}_{\mathrm{a}}\left({ }^{\circ} \mathrm{C}\right)$ \\
\hline XGWM526 & $\mathrm{Yr} 7$ & CAATAGTTCTGTGAGAGCTGCG & CCAACCCAAATACACATTCTCA & $55^{\circ} \mathrm{C}$ \\
\hline XGWM582 & $\mathrm{Yr} 9$ & AAGCACTACGAAAATATGAC & TCTTAAGGGGTGTTATCATA & $50^{\circ} \mathrm{C}$ \\
\hline XGWM413 & Yr15 & TGCTTGTCTAGATTGCTTGGG & GATCGTCTCGTCCTTGGCA & $54^{\circ} \mathrm{C}$ \\
\hline XGWM295 & Yr18 & GTGAAGCAGACCCACAACAC & GACGGCTGCGACGTAGAG & $55^{\circ} \mathrm{C}$ \\
\hline XGWM11 & Yr26 & GGATAGTCAGACAATTCTTGTG & GTGAATTGTGTCTTGTATGCTTCC & $50^{\circ} \mathrm{C}$ \\
\hline XGWM18 & $\operatorname{Yr} 26$ & TGGCGCCATGATTGCATTATCTC & GGTTGCTGAAGAACCTTATTTAGG & $50^{\circ} \mathrm{C}$ \\
\hline XGWM273 & YrH52 & ATTGGACGGACAGATGCTTT & AGCAGTGAGGAAGGGGATC & $55^{\circ} \mathrm{C}$ \\
\hline
\end{tabular}

$\mathrm{T}_{\mathrm{a}}=$ annealing temperature.

\section{RESULTS}

\section{Simple-sequence motifs among wheat genotypes}

Seven SSR markers genetically linked to $Y r$ genes were characterized in six bread wheat cultivars and amplified PCR products successfully. Of the SSRs analyzed, 50\% of the primer pairs amplified monomorphic [XGWM582 (150 bp), XGWM295 (250 bp), XGWM18 (200 bp)] and rest of the primer pairs amplified polymorphic [XGWM526 (140160 bp), XGWM413 (95-100-110 bp), XGWM11 (200 bp) and XGWM273 (170-180-190200 bp)] PCR products. Multiple discrete PCR products were observed among di- and tetranucleotide SSR markers. There were more dinucleotide repeats than tetranucleotide repeats in the six bread wheat genotypes used in this study.

Among the dinucleotide repeat classes of microsatellites, the most abundant repeat motifs were GA, TC, and CA. Based on the results of DNA sequence analysis, the repeated motifs and the numbers were evaluated for each SSR marker. After evaluation, 2 (140 and $160 \mathrm{bp}), 3$ (95, 100 and $110 \mathrm{bp})$ and $4(170,180,190$, and $200 \mathrm{bp})$ different allele profiles were observed for TC, AG and GA motifs, respectively (Figure 1).

GA was significantly more common than the other dinucleotide motifs. It was observed that the most GA motifs are in Aytin98 and the least GA motifs are in Harmankaya99, among the genotypes used in study. The distribution of other repeat motifs was also calculated. For example, the CA motif is the most common in PI178383 and the least in Sonmez2001-Aytin98, the TC motif is the most frequent in Izgi2001 and the least in PI178383 and Harmankaya99. In addition, the most repeated motifs were found in 


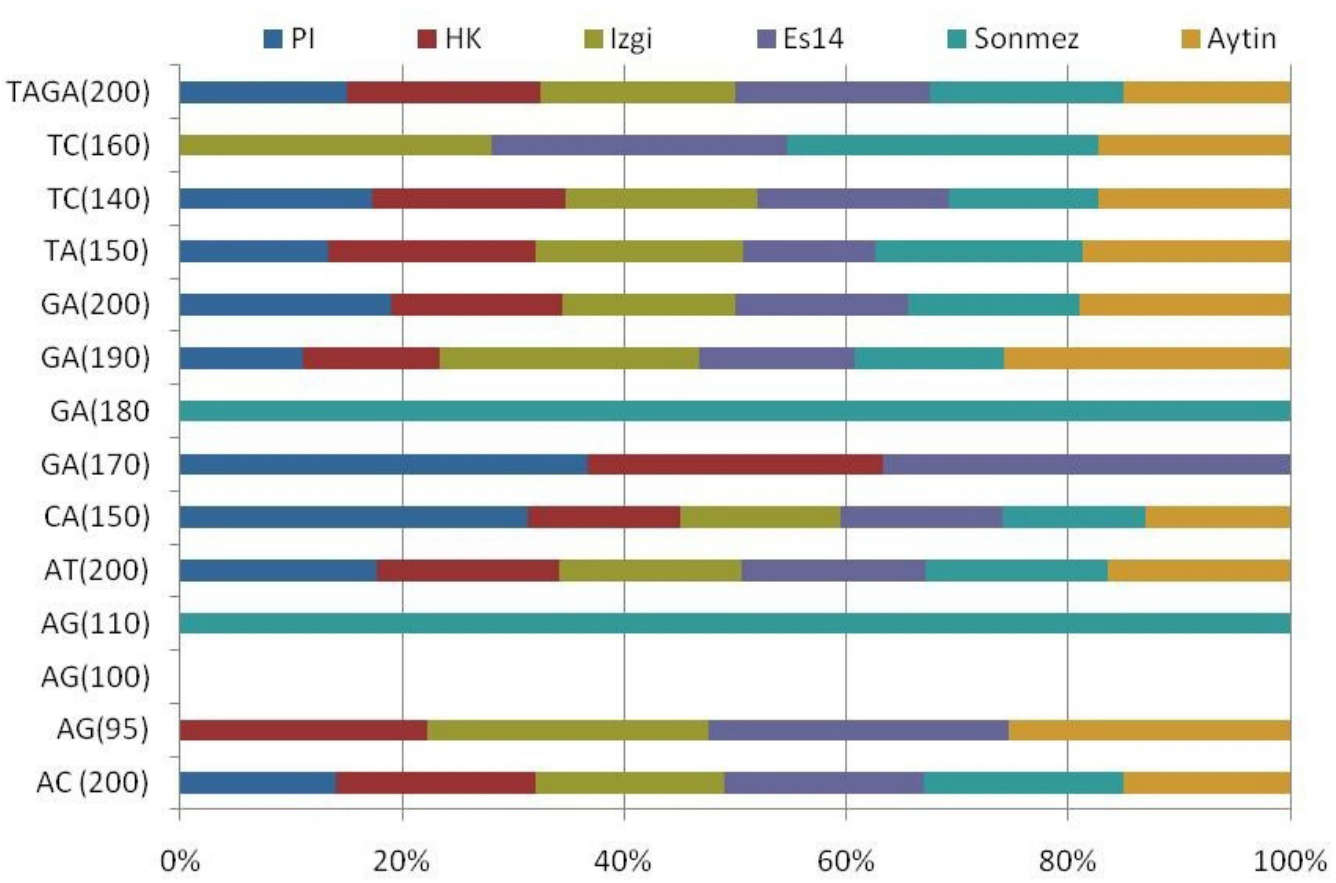

Figure 1. Mean tandem repeat number of microsatellite motifs for 6 different wheat's genomic DNA.

Sonmez2001 but the least in Harmankaya99 in terms of total number of repeated motifs (Table 2).

Frequencies of different types of microsatellite repeat motifs according to seven microsatellite primers derived from yellow rust gene specific markers located in 1BS (Yr15-Xgwm413, Yr9-Xgwm582, Yr26-Xgwm11, Yr26-Xgwm18 and YrH52-Xgwm273), 2B (Yr7-Xgwm526) and 7D (Yr18-Xgwm295) were also calculated for 6 wheat cultivars (Figure 2).

According to these results, GA was the most and TAGA was the least found.

\section{Conserved regions and sequence differences among wheat genotypes}

DNA sequence analysis of PCR products was performed for each molecular marker in order to identify conserved regions and single nucleotide differences. According to ClustalW analysis of DNA sequences, the most single nucleotide polymorphism was obtained with $\mathrm{Xgwm} 413$ (Yrl5) marker and the least single nucleotide polymorphism was obtained with Xgwm273 (YrH52) marker (Table 2). All insertions, deletions and single nucleotide changes were taken into consideration and it was detected that Xgwm526 (160 bp) and Xgwm273 (170-180-190 bp) have the most conserved regions molecular markers among cultivars used in the study. 


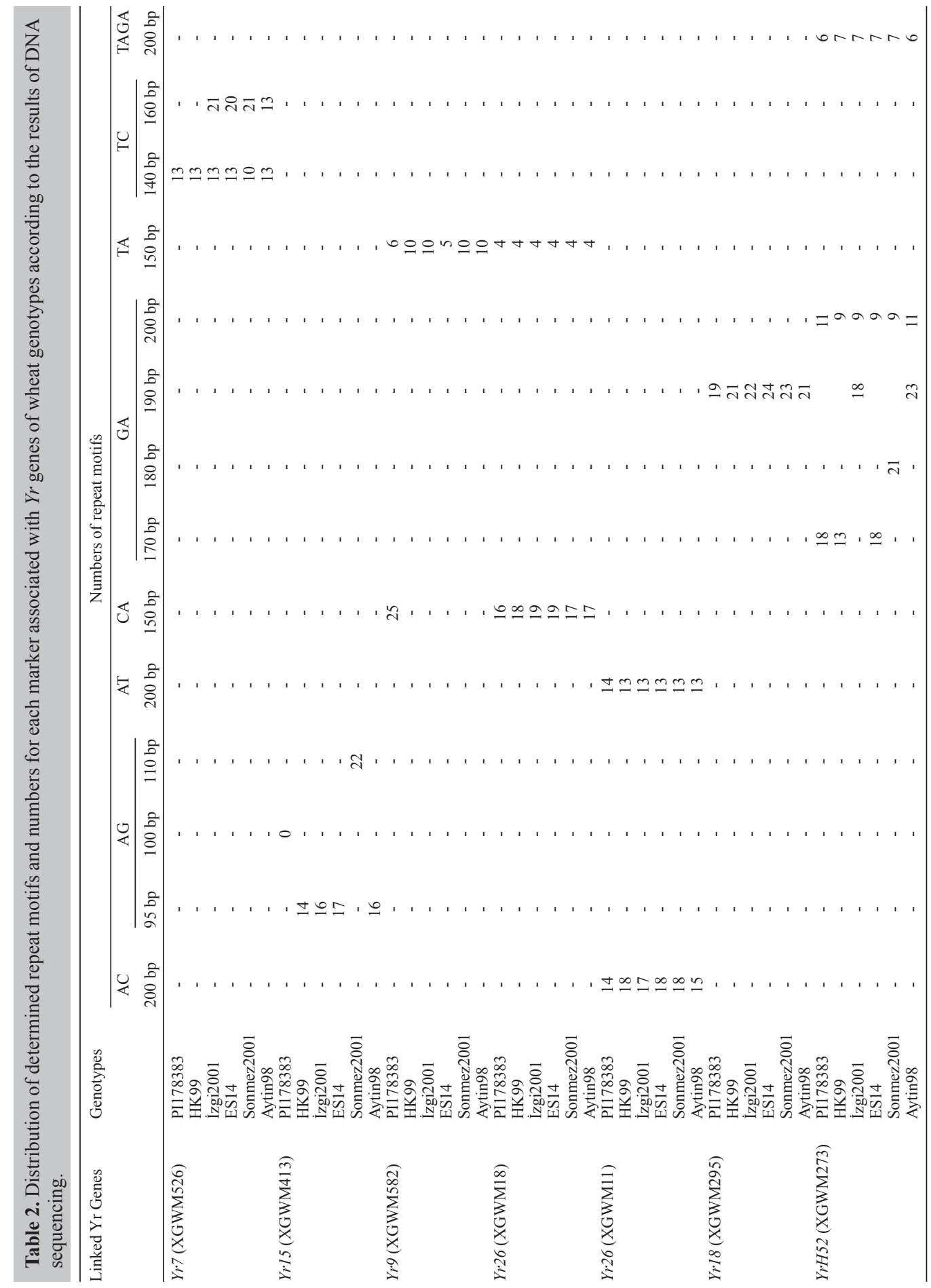




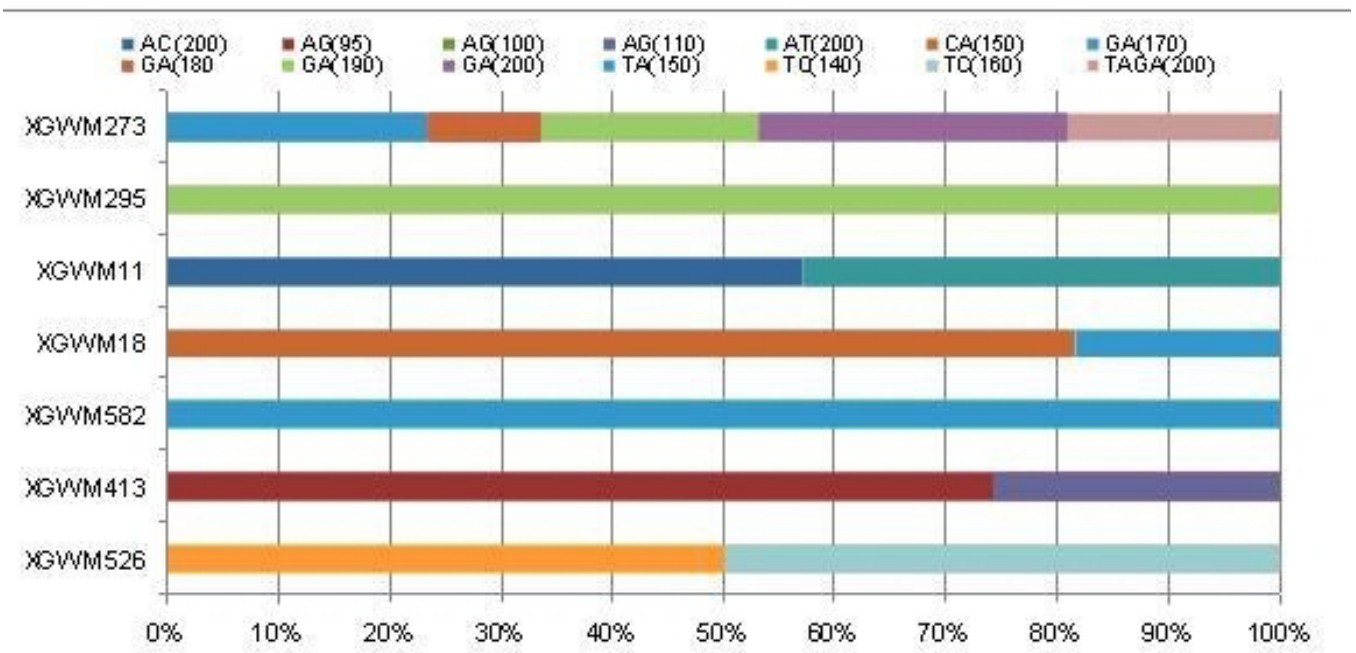

Figure 2. Frequencies of different types of microsatellite repeat motifs according to seven microsatellite primers specific to gene-rich region in 6 different wheat cultivars.

\section{DISCUSSION}

Repeat type is one of the important factors that have been found to affect the stability of microsatellites (Schlotterer, 2000; Ellegren, 2004). In the present study, we compared the percentage of repeat motifs in six bread wheat genotypes. Our study compared the polymorphism rate of di- and tetranucleotide microsatellites. The results indicate the dinucleotide microsatellites have the highest rate of polymorphism, while the tetranucleotide microsatellites are the least polymorphic. It has also been reported that the base composition of the repeat motifs may play a role in the variations of microsatellites. (GT)n and (GA)n motifs were found to repeat respectively every $704 \mathrm{~kb}$ and $440 \mathrm{~kb}$ in the wheat genome (Roder et al., 1995). In addition, the number of GA repeat motif is more than the number of GT repeat motifs in wheat (Plaschke et al., 1995), barley (Struss and Plieske, 1998), rice (Wu and Tanksley, 1993), apple (Guilford et al., 1997) and Brassica napus (Lagercrantz et al., 1993; Szewc-McFadden et al., 1996). Because there are many GA and GT repeat motifs in wheat, eight wheat varieties have been scanned with designed primers using these motifs (Koike et al., 2006). GA was also shown to be the most abundant motif in grasses (Temnykh et al., 2001; Kantety et al., 2002; Nicot et al., 2004; Parida et al., 2006). It was revealed that the GA repeat motif has the highest polymorphism rate (approx. 74\%), whereas the GT repeat motif has the lowest (about 15\%). Similarly, our results indicate that there are differences in the polymorphism rate among the three dinucleotide motifs (GA, TC, and CA) and that the GA motif was the most abundant repeat motifs in all wheat genotypes.

Stepien et al. (2007) determined the repeat motif and number of Xgwm18 marker as $(\mathrm{CA})_{17} \mathrm{GA}(\mathrm{TA})_{4}$ in 53 Polish wheat cultivars. In our study, we found the repeat motif and number of the $X g w m 18$ marker to be $(\mathrm{CA})_{16}(\mathrm{TA})_{4}(\mathrm{CA})_{17}(\mathrm{TA})_{4},(\mathrm{CA})_{18}(\mathrm{TA})_{4}$ and $(\mathrm{CA})_{19}(\mathrm{TA})_{4}$ in PI178383, Sonmez2001-Aytin98, Harmankaya99 and Izgi2001-ES14, respectively. Nevertheless, no found GA repeat motif was obtained by screening any genotypes with this marker. 
As a result (i) motifs and the numbers of repeat regions (ii) single-nucleotide differences (iii) and the most protected areas were detected, which belonged to the sequences obtained from DNA sequence analysis with primers for the markers associated with $\mathrm{Yr}$ genes in the gene-rich regions of wheat chromosomes, and the original differences were thereby detected among the cultivars studied. By designing new primers based on these original differences, new markers can be obtained, and these markers can be used in screening populations that show segregation in terms of yellow rust disease. Resistant and susceptible wheat genotypes used in this work, have already been used by our research group for the development of molecular markers for yellow rust resistance. In this frame, Temel et al. (2008) investigated the sequence differences of yellow rust resistance gene "Yr10" in seven winter-type bread wheat genotypes, and the results obtained from this work indicate that (1) Yr10 gene sequence is present in all of these varieties (2) the divergence between the varieties is raised from the variations in the second exon, an (3) the first exon is more conserved than the second one in all genotypes. Sequence variations could affect gene expression and could weaken yellow rust resistance. In another work by our group, Akfirat et al. (2010) used bulk segregant analysis (BSA) to identify molecular markers associated with yellow rust disease resistance in a Izgi2001 x ES14 cross. This analysis showed that $81 \%$ of the wheat genotypes known to be yellow rust resistant had the SSR marker Xgwm382. Similarly, one EST-SSR marker (Pk54) has been identified in a PI178383 x Harmankaya99 cross. A total of 108 wheat genotypes differing in yellow rust resistance were screened with $P k 54$, and $68 \%$ of the wheat genotypes known to be yellow rust resistant had Pk54 (Ercan et al., 2010), further suggesting that the presence of these markers correlate with yellow rust resistance in diverse wheat germplasm.

Based on the above mentioned studies, the characterization of SSR markers regarding the repeat numbers, type of motifs and sequence differences could have important implications for molecular marker-assisted selection strategies and pyramiding of the yellow rust resistant genes in wheat breeding programs.

\section{ACKNOWLEDGMENTS}

Research supported by TUBITAK KAMAGt (\#105G075) and the Marmara University Scientific Research Committeet (\#FEN-C-YLP-110908-0230, 2009). The authors thank Dr. Necmettin Bolat for providing the plant material and Aysen Yumurtaci for assisting with the DNA sequence analysis.

\section{REFERENCES}

Akfirat SF, Aydin Y, Ertugrul F, Hasancebi S, et al. (2010). A microsatellite marker for yellow rust resistance in wheat. Communications 38: 203-211.

Akkaya MS, Bhagwat AA and Cregan PB (1992). Length polymorphisms of simple sequence repeat DNA in soybean. Genetics 132: 1131-1139.

Bennett MD and Smith JB (1976). Nuclear DNA amounts in angiosperms. Philos. Trans. R. Soc. Lond. B Biol. Sci. 274: 227-274.

Ellegren H (2000). Microsatellite mutations in the germline: implications for evolutionary inference. Trends Genet. 16: 551-558.

Ellegren H (2004). Microsatellites: simple sequences with complex evolution. Nat. Rev. Genet. 5: 435-445.

Ercan S, Ertugrul F, Aydin Y, FS Akfirat, et al. (2010). An EST-SSR marker linked with yellow rust resistance in wheat. Biol. Plant. 54: 691-696. 
Guilford P, Prakash S, Zhu JM and Rikkerink E (1997). Microsatellites in Malus x domestica (apple): abundance, polymorphism and cultivar identification. Theor. Appl. Genet. 94: 249-254.

Kantety RV, La RM, Matthews DE and Sorrells ME (2002). Data mining for simple sequence repeats in expressed sequence tags from barley, maize, rice, sorghum and wheat. Plant Mol. Biol. 48: 501-510.

Koike M, Kawaura K, Ogihara Y and Torada A (2006). Isolation and characterization of SSR sequences from the genome and TAC clones of common wheat using the PCR technique. Genome 49: 432-444.

Lagercrantz U, Ellegren H and Andersson L (1993). The abundance of various polymorphic microsatellite motifs differs between plants and vertebrates. Nucleic Acids Res. 21: 1111-1115.

Maia LC, Souza VQ, Kopp MM and Carvalho FI (2009). Tandem repeat distribution of gene transcripts in three plant families. Genet. Mol. Biol. 32: 822-833.

McDowell JM and Woffenden BJ (2003). Plant disease resistance genes: recent insights and potential applications. Trends Biotechnol. 21: 178-183.

McNeal FH, Konzak CF, Smith EP and Tade WS (1971). A Uniform System for Recording and Processing Cereal Research Data. Agricultural Research Service, United States Department of Agriculture, Washington, 42.

Morgante M and Olivieri AM (1993). PCR-amplified microsatellites as markers in plant genetics. Plant J. 3: 175-182.

Nakitandwe J, Trognitz F and Trognitz B (2007). Reliable allele detection using SNP-based PCR primers containing Locked Nucleic Acid: application in genetic mapping. Plant Methods 3: 2.

Neff BD and Gross MR (2001). Microsatellite evolution in vertebrates: inference from AC dinucleotide repeats. Evolution 55: $1717-1733$.

Nicot N, Chiquet V, Gandon B, Amilhat L, et al. (2004). Study of simple sequence repeat (SSR) markers from wheat expressed sequence tags (ESTs). Theor. Appl. Genet. 109: 800-805.

Parida SK, Anand Raj KK, Dalal V, Singh NK, et al. (2006). Unigene derived microsatellite markers for the cereal genomes. Theor. Appl. Genet. 112: 808-817.

Plaschke J, Ganal MW and Roder MS (1995). Detection of genetic diversity in closely related bread wheat using microsatellite markers. Theor. Appl. Genet. 91: 1001-1007.

Roder MS, Plaschke J, Konig SU, Borner A, et al. (1995). Abundance, variability and chromosomal location of microsatellites in wheat. Mol. Gen. Genet. 246: 327-333.

Roder MS, Korzun V, Gill BS and Ganal MW (1998). The physical mapping of microsatellite markers in wheat. Genome 41: $278-283$

Schlotterer C (2000). Evolutionary dynamics of microsatellite DNA. Chromosoma 109: 365-371.

Shaheen T, Zafar Y and Rahman M (2010). Detection of Single Nucleotide Polymorphisms in the Conserved ESTs Regions of Gossypium arboretum. Electronic Journal of Biotechnology, Available at [http://dx.doi.org/10.2225/ vol13-issue5-fulltext-3]. Accessed.

Song W and Henry RJ (1995). Molecular analysis of the DNA polymorphism of wild barley (Hordeum spontaneum) germplasm using the polymerase chain reaction. Genet. Res. Crop Evol. 42: 273-280.

Stepien L, Mohler V, Bocianowski J and Koczyk G (2007). Assessing genetic diversity of Polish wheat (Triticum aestivum) varieties using microsatellite markers. Genet. Res. Crop Evol. 54: 1499-1506.

Struss D and Plieske J (1998). The use of microsatellite markers for detection of genetic diversity in barley populations. Theor. Appl. Genet. 97: 308-315.

Szewc-McFadden AK, Kresovic S, Bliek SM and Mitchell SE (1996). Identification of polymorphic, conserved simple sequence repeats (SSRs) in cultivated Brassica species. Theor. Appl. Genet. 93: 534-538.

Tautz D, Trick M and Dover GA (1986). Cryptic simplicity in DNA is a major source of genetic variation. Nature 322: 652-656.

Temel A, Akfirat SF, Ertugrul F and Yumurtaci A (2008). Yr10 gene polymorphism in bread wheat varieties. Afr. J. Biotechnol. 14: 2328-2332.

Temnykh S, DeClerck G, Lukashova A, Lipovich L, et al. (2001). Computational and experimental analysis of microsatellites in rice (Oryza sativa L.): frequency, length variation, transposon associations, and genetic marker potential. Genome Res. 11: 1441-1452.

Weber JL (1990). Informativeness of human (dC-dA)n.(dG-dT)n polymorphisms. Genomics 7: 524-530.

Weber JL and May PE (1989). Abundant class of human DNA polymorphisms which can be typed using the polymerase chain reaction. Am. J. Hum. Genet. 44: 388-396.

Weining S and Langridge P (1991). Identification and mapping of polymorphism in cereals based on the polymerase chain reaction. Theor. Appl. Genet. 82: 209-216.

Wu KS and Tanksley SD (1993). Abundance, polymorphism and genetic mapping of microsatellites in rice. Mol. Gen. Genet. 241: 225-235. 